Supplement of Atmos. Chem. Phys., 14, 8343-8367, 2014

http://www.atmos-chem-phys.net/14/8343/2014/

doi:10.5194/acp-14-8343-2014-supplement

(C) Author(s) 2014. CC Attribution 3.0 License.

(c) (i)

Supplement of

\title{
Land-surface controls on afternoon precipitation diagnosed from observational data: uncertainties and confounding factors
}

B. P. Guillod et al.

Correspondence to: B. P. Guillod (benoit.guillod@env.ethz.ch) and S. I. Seneviratne (sonia.seneviratne@env.ethz.ch) 


\section{S1 North American Regional Reanalysis: sensitivity of EF-precipitation relationship to the time period and to the selection of potentially convective days}

Although the NARR product is available from 1979 to present, we use only a sub-period with available data in other datasets. Since most of the analyses presented in the main part of this paper include data from both NARR and the GLEAM-NEXRAD combination, computations are restricted to days when data is available from the GLEAM-NEXRAD combination (years 1995-2007 minus some gaps). In order to test the impact of the reduced amount of data, Fig. S1 displays TFS ${ }^{\star}$ computed from NARR using years 1979-2007 (left) and using only years and days with data in the GLEAM-NEXRAD combination (right). This leads to a reduced number of sites with significant positive TFS ${ }^{\star}$ and to slightly lower values. Nonetheless, the overall patterns remain highly similar.
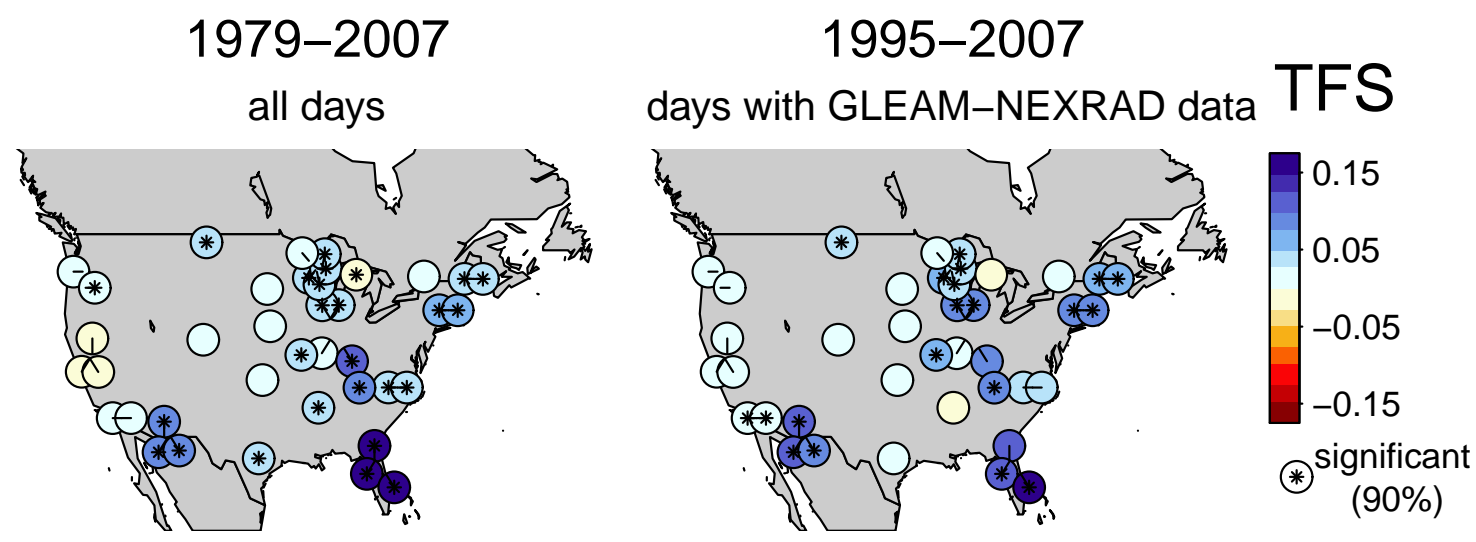

Figure S1: TFS ${ }^{\star}$ for different time periods in NARR. Left: 1979-2007. Right: Subset of days when data is also available from the GLEAM-NEXRAD combination (years 1995-2007 minus some periods with gaps).

In addition, the impact of the criteria for the selection of convective days (see Section $3 \mathrm{~b}$ ) is tested in Fig. S2, showing results for our radiation-based criterion (left) and (right) the original criterion from Findell et al. (2011). The patterns of TFS ${ }^{\star}$ are highly similar using either criterion, albeit our criterion yields slightly lower values. The radiation criterion is used in this study in order to allow for the same criterion for all datasets. 
Criteria for the selection of potentially convective days Global radiation CTP

\section{TFS}
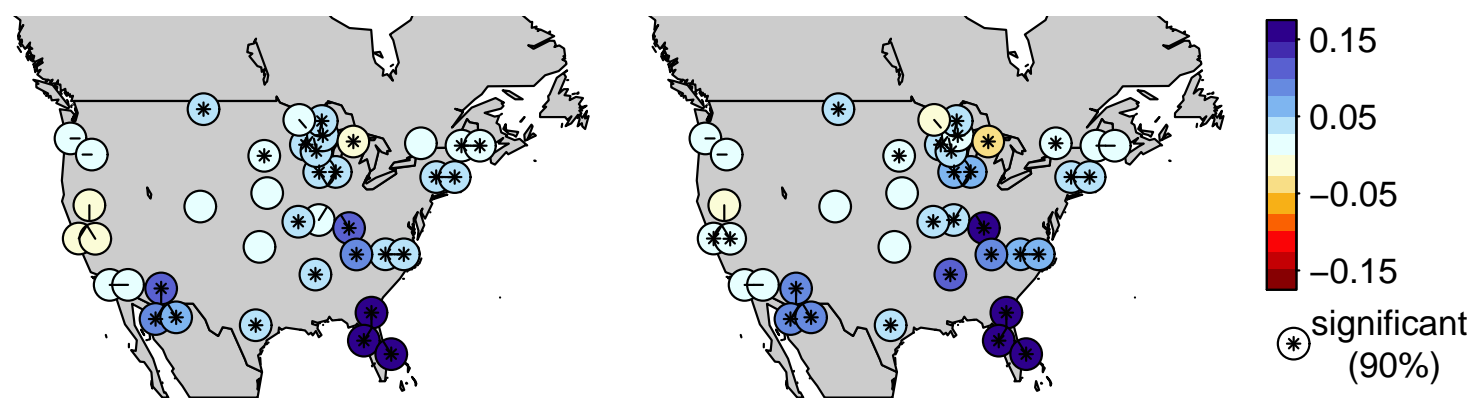

Figure S2: TFS ${ }^{\star}$ for different criteria for the selection of potentially convective days in NARR. Left: Our radiation-based criterion. Right: CTP-based criterion from Findell et al. (2011). Days with morning precipitation are removed in both cases. The computation is restricted to 1979-2003 due to readily available CTP data over that period. The resulting maps show that the use of our radiation-based criterion instead of the original CTP-criterion leads to highly similar values of TFS*. 


\section{S2 Sensitivity of GLEAM to the precipitation dataset used as input}

As described in the main part of this paper (see Section 2d), GLEAM-derived estimates of before-noon EF are computed using precipitation from NEXRAD as input. Other precipitation products could be used, but have to match the required timing described in Section 2d. Table S1 shows the definition of days for two common daily precipitation datasets, CPC-Unified (Chen et al., 2008) and GPCP-1DD (Huffman et al., 2001). While

Table S1: Definition of the day (timing) for the discussed precipitation datasets. PERSIANN and NEXRAD are available at a 3-hourly resolution and are used in the analysis. Two common daily precipitation datasets, CPC-Unified and GPCP1DD are described as follows: For precipitation on day $i$, the timing definition in UTC and US local time are shown. The US local timings for the West coast and the East coast are expressed in standard time (i.e., local time without the offset for daylight saving time).

\begin{tabular}{|l|c|c|l|l|}
\hline Dataset & $\begin{array}{c}\text { Timing definition (UTC) } \\
\text { for day } i\end{array}$ & $\begin{array}{c}\text { US local timing } \\
\text { West (East) coast }\end{array}$ & Reference & Shown in \\
\hline CPC-Unified & $\begin{array}{c}\text { Country-dependent } \\
\text { USA: from 12z, day }(i-1) \\
\text { to 12z, day } i\end{array}$ & $\begin{array}{c}\text { 4AM (7AM), day }(i-1) \\
\text { to } \\
\text { 4AM (7AM), day } i\end{array}$ & Chen et al. (2008) & Figure S3 \\
\hline GPCP-1DD & UTC day (0z-0z) & $\begin{array}{c}\text { 4PM (7PM), day }(i-1) \\
\text { to } \\
\text { UPM (7PM), day } i\end{array}$ & Huffman et al. (2001) & not suitable \\
\hline PERSIANN & \multicolumn{2}{|r|}{ 3-hourly resolution } & $\begin{array}{l}\text { Hsu et al. (1997) } \\
\text { http://www.ncdc. } \\
\text { noaa.gov/oa/radar/ } \\
\text { radarresources.html }\end{array}$ & main paper \\
\hline NEXRAD & \multicolumn{2}{|r|}{ 3-hourly resolution } & & Figure S3 \\
\hline
\end{tabular}

GPCP-1DD has a clearly defined timing that is consistent globally, it does not fit our experimental setting with GLEAM, since precipitation during roughly the 12 hours preceding the estimated EF would be missed. CPC-Unified, on the other hand, fits our requirements over the US (day ending in the morning), although one cannot exclude that afternoon precipitation is included due to possibly different reporting times between different PIs.

We restricted the analyses in the main part of the paper to a version of GLEAM forced by NEXRAD precipitation, but Fig. S3 shows results with CPC-Unified and PERSIANN (a 3-hourly satellite product, Hsu et al., 1997), two other suitable precipitation forcings. For the TFS $^{\star}$ computation, NEXRAD precipitation is used in all cases. All three estimates display similar West-East gradients, highlighting the robustness of our GLEAM-based results with respect to precipitation input. Nonetheless, TFS ${ }^{\star}$ values tend to be lower and less significant with CPC and PERSIANN. 

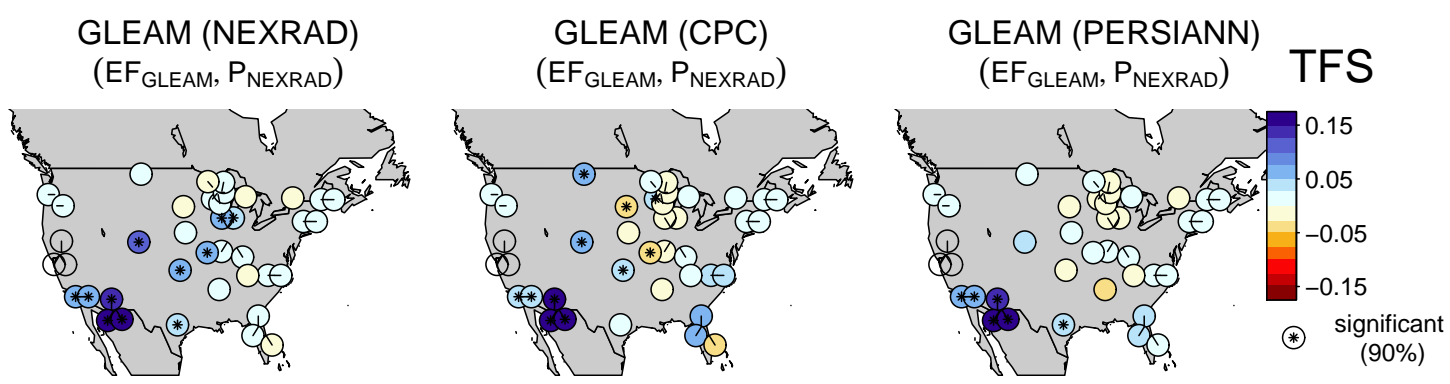

Figure S3: Triggering Feedback Strength $\left(\mathrm{TFS}^{\star}\right)$ based on remote-sensing products (GLEAM, NEXRAD) where EF is computed using different precipitation datasets as input (NEXRAD, CPC, PERSIANN). Note that precipitation from NEXRAD is used for TFS computation for all three datasets. 


\section{S3 EF correlations at longer time scales}

Figure 5 in the main text highlights weak correlations between before-noon EF estimates from different datasets. Figure S4 displays correlations of 10-days and monthly means of before-noon EF values. Correlations are higher than for daily values of before-noon EF. Nonetheless, correlations remain small, mostly around 0.5, highlighting uncertainties in EF even on longer time scales. The correlations become less significant for longer time scales due to the lower number of data points. Using EF anomalies instead of absolute values leads to similar results, albeit with slightly lower correlations (not shown).
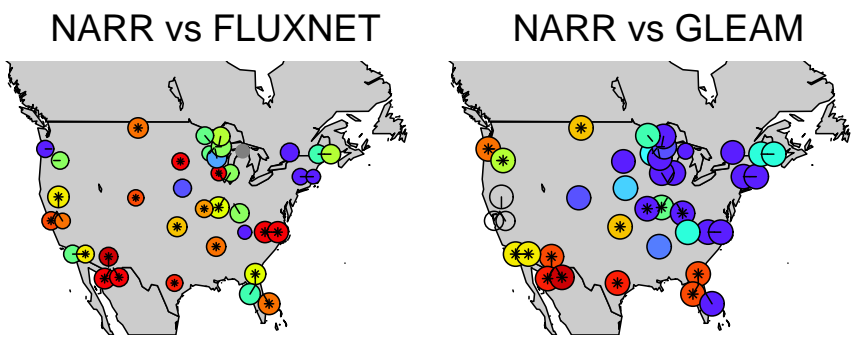

FLUXNET vs GLEAM

(a) 10 days
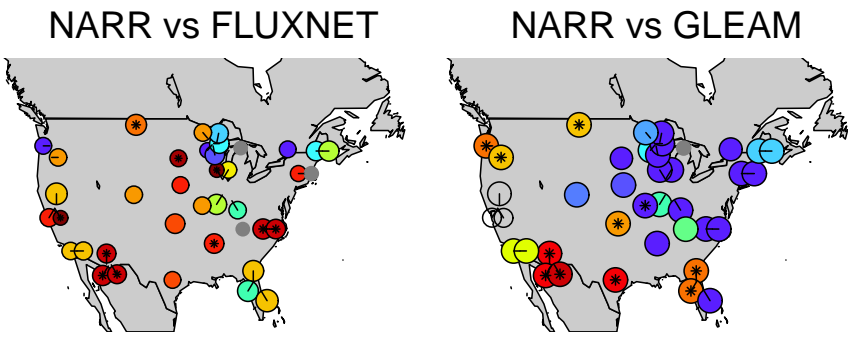

FLUXNET vs GLEAM

(b) monthly
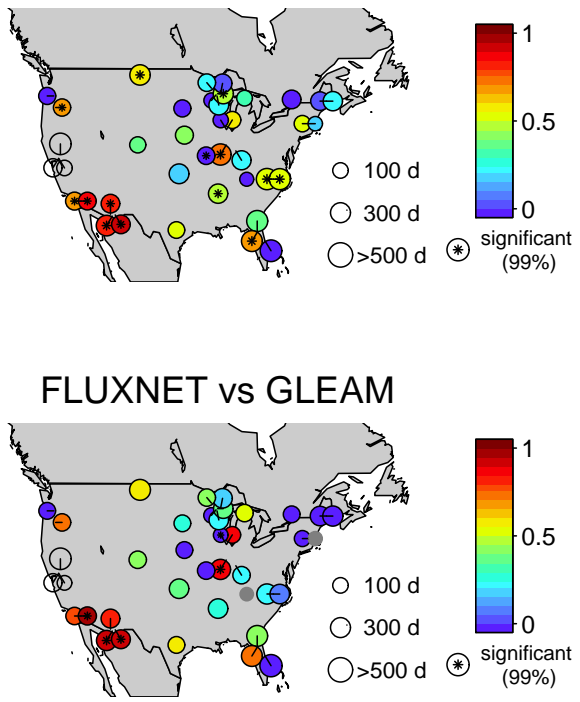

Figure S4: Correlations of JJA before-noon EF between different datasets for (a) 10-days averages and (b) monthly averages. The size of the dots indicates the number of days included in the computation, and significant correlations at a $99 \%$ level are indicated by a black star. Empty dots for GLEAM indicate sites with unreliable NEXRAD (and thus GLEAM) data. 


\section{S4 Decomposition of the NARR signal: full NARR time period}

Section 6 decomposes the EF-precipitation relationship from NARR into its components of land evaporation and the atmospheric forcing (Fig. 10). While in the paper all analyses with NARR are conducted for days also available in GLEAM-NEXRAD for consistency, the analysis of Fig. 10 can easily be extended to include the whole NARR time period (1979-2007). This is particularly useful for the last row of Fig. 10, where the low number of days without interception storage leads to noisy results. Fig. S5 shows the results of the computations for the 1979-2007 period and confirms that, once the effect of interception storage is removed, the atmospheric forcing on $\mathrm{EF}$ via $\mathrm{EF}_{\text {pot }}$ seems to play a greater role than soil moisture over the Eastern US. 
(a) $\Delta \Gamma(E F)$
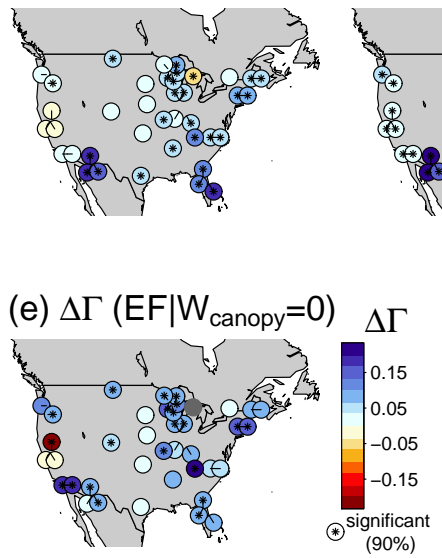

(h)

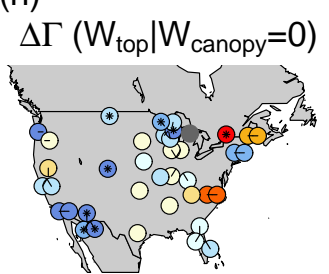

(b) $\Delta \Gamma\left(\mathrm{W}_{\text {top }}\right)$

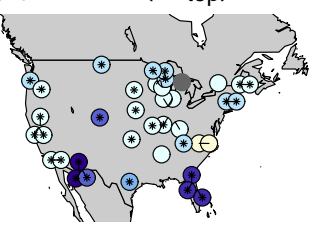

(f) (c) $\Delta \Gamma\left(\mathrm{W}_{\text {roots }}\right)$

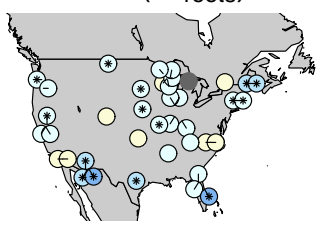

$\Delta \Gamma(E F)-$

$\Delta \Gamma\left(E F \mid \mathrm{W}_{\text {canopy }}=0\right)$

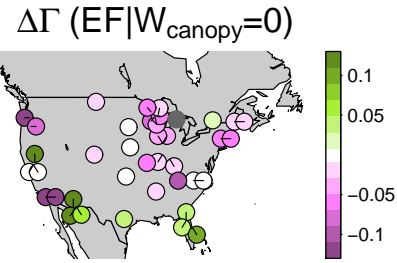

(i)

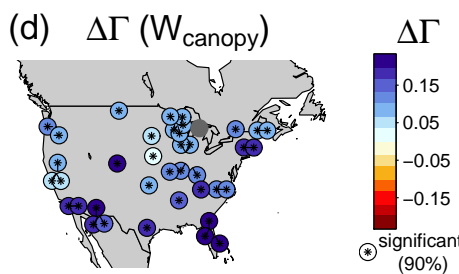

(g) Percentage of days with $\mathrm{W}_{\text {canopy }}>0$

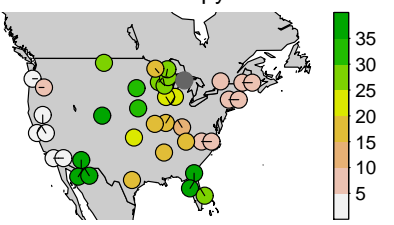

(j)
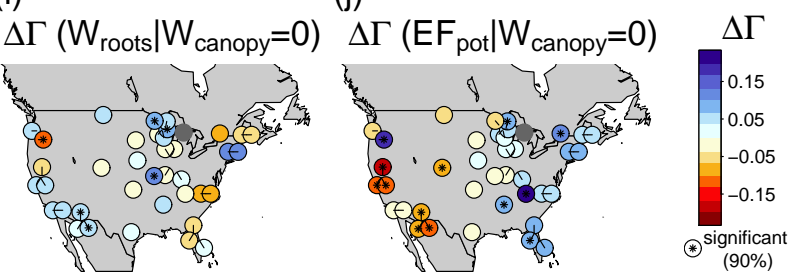

Figure S5: Same as Fig. 10 in main paper but for the longer NARR time period (19792007): Identification of the drivers of the EF-precipitation relationship in NARR. Top row: difference in the probability of afternoon rainfall, $\Delta \Gamma(X)$ on days with high vs. low $X$, where $X$ is the before-noon value of the different drivers. From left to right, $X$ is (a) EF and (b-d) the three water storage terms that control EF: (b) surface soil moisture ( $W_{\text {top }}$, controls bare soil evaporation), (c) root zone soil moisture ( $W_{\text {root }}$, controls plant transpiration) and (d) vegetation (canopy) interception storage ( $W_{\text {canopy }}$, controls interception evaporation). Middle row: (e) $\Delta \Gamma(\mathrm{EF})$ computation restricted to days without canopy storage, (f) difference between $\Delta \Gamma(\mathrm{EF})$ computed with all days and with days without vegetation interception storage, and $(\mathrm{g})$ percentage of days with interception storage. Bottom row: $\Delta \Gamma(X)$ restricted to days without interception storage where $X$ is (h) surface soil moisture, (i) root zone soil moisture and $(\mathbf{j})$ potential $\mathrm{EF}\left(\mathrm{EF}_{\mathrm{pot}}\right)$. High (low) $X$ refer to values higher (lower) than the 60th (40th) percentile of $X$, i.e. $\Delta \Gamma(X)=\Gamma\left(r \mid X>X_{\mathrm{Q} 60}\right)-\Gamma\left(r \mid X \leq X_{\mathrm{Q} 40}\right)$. Values significantly different from 0 at the $90 \%$ level are indicated by a black star. Grey dots indicate sites without day with afternoon precipitation. 


\section{S5 Interception in NARR: before-noon storage source}

GLEAM assumes that interception storage at the time of the estimated EF (9-12LT) is negligible, because days with morning (6-12LT) precipitation are removed from the analysis and intercepted water is known to evaporates within a few hours, even at night. However, our analysis from Section 6 (see also Sect. S4 in this Supplement) suggests that there is some intercepted water left during the before-noon time period in a substantial number of days in NARR, and that this could explain part of the EF-precipitation relationship over the Eastern US. In Sect. 6, we mention that this interception storage might be provided by precipitation on the previous day, a possibly non-realistic feature. Indeed, like many models, the Noah land surface model used in NARR uses a parameterization of interception evaporation which relies on potential evaporation (i.e., mostly net radiation), leading to low (or no) evaporation at night. This would be inconsistent with field studies, which have shown that interception evaporation is typically as high during the night as during the day and suggest that advected energy or negative sensible heat flux, rather than radiation, drive interception evaporation (e.g. Pearce et al., 1980; Asdak et al., 1998; Holwerda et al., 2012).

To support our hypothesis, Fig. S6 displays composites of time series of the interception storage (left) and precipitation (right) in NARR, for 6 representative sites in the Eastern US and for days without morning precipitation. As expected, the interception storage is filled up by rainfall during the afternoon or evening of the previous day. In spite of low precipitation during the night (in most cases, no precipitation at all), intercepted water does not evaporate until the before-noon time period, supporting our hypothesis. Note that the interception storage capacity in NARR is only $0.5 \mathrm{~mm}$, and that this amount would re-evaporate within a few hours (e.g. in less than $1.5 \mathrm{~h}$ with the night-time interception evaporation rate of $0.37 \mathrm{~mm} / \mathrm{h}$ from Pearce et al., 1980).

Thus, the parameterization of interception in NARR appears to underestimate the evaporation of intercepted water at night, which leads to an overestimation of morning interception storage and related evaporation. 
interception storage [mm]

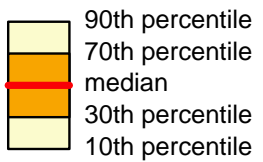

US-Goo

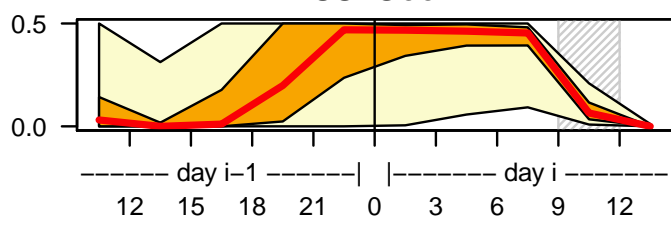

US-WBW

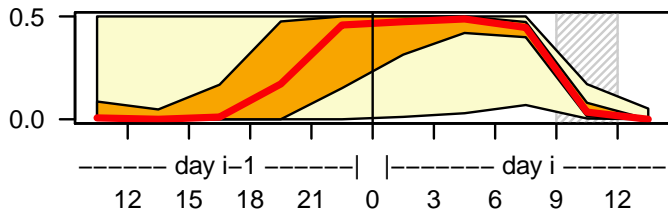

US-Dk1

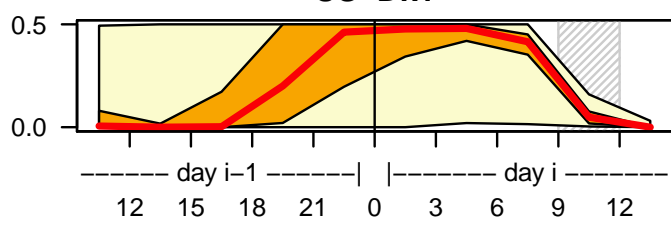

US-MMS

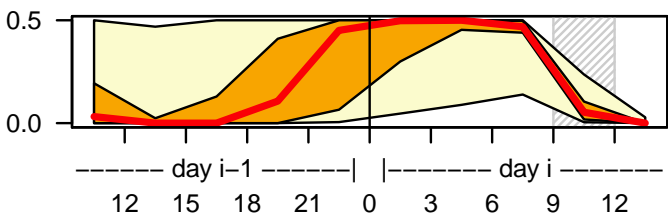

US-Bo1

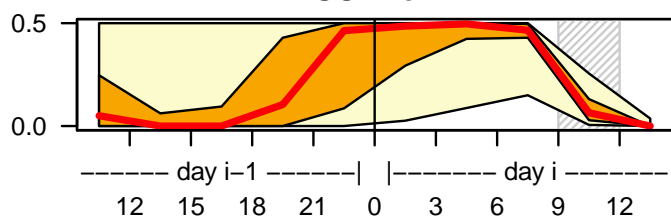

US-SP2

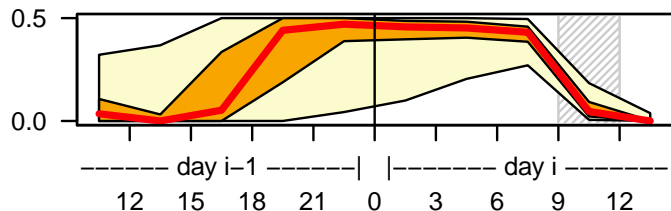

precipitation [mm/3h]

90th percentile

70th percentile

median

30th percentile

10th percentile

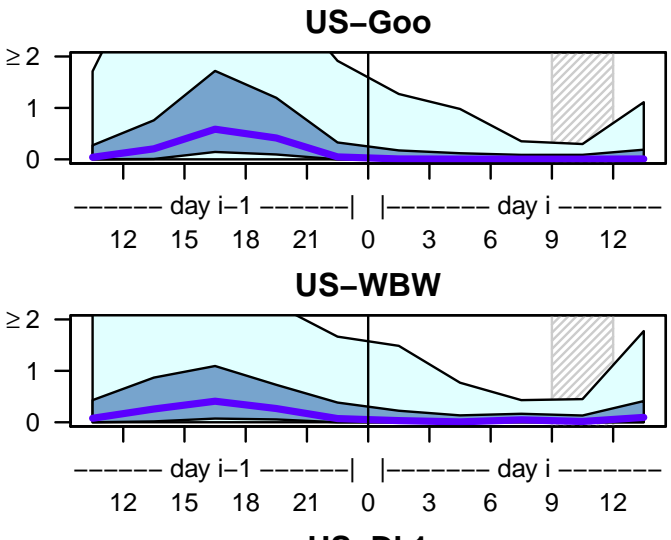

US-Dk1

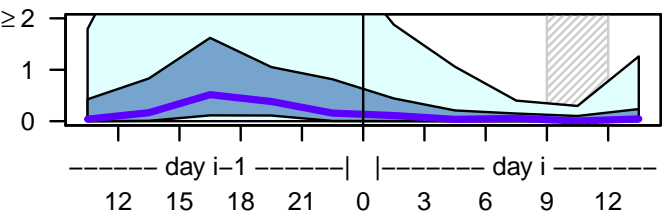

US-MMS

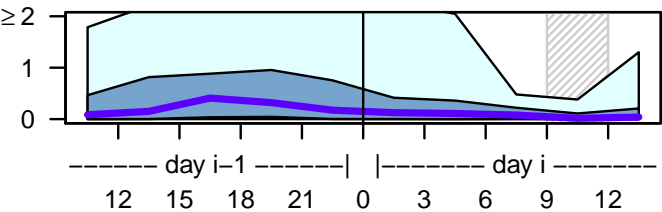

US-Bo1

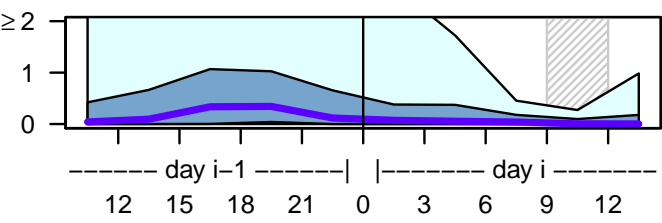

US-SP2

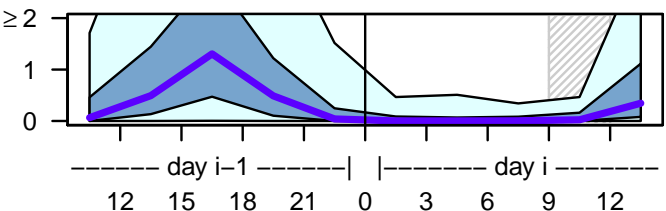

Figure S6: Composite time series of interception storage (left) and precipitation (right) in NARR at 6 sites in the Eastern US, on days without morning precipitation $(<1 \mathrm{~mm}$ from $6-12 \mathrm{LT})$. The before-noon time period is hatched in grey and the previous $24 \mathrm{~h}$ are displayed (day and hour of the day indicated on the horizontal axes), with midnight indicated by a vertical black line. The thick orange/blue lines indicate the median of all cases, while color shading indicates percentiles of the time series according to the legend shown at the top. Interception storage capacity (i.e., maximum value) is defined as $0.5 \mathrm{~mm}$ in NARR. In most cases, interception storage is filled in the afternoon or evening of the previous day and does not re-evaporate at night in spite of no or low precipitation. 


\section{References}

Asdak, C., Jarvis, P. G., and Gardingen, P. V.: Evaporation of intercepted precipitation based on an energy balance in unlogged and logged forest areas of central Kalimantan, Indonesia , Agric For Meteorol, 92, 173-180, doi:http:// dx.doi.org/10.1016/S0168-1923(98)00097-5, URL http://www.sciencedirect.com/ science/article/pii/S0168192398000975, 1998.

Chen, M., Shi, W., Xie, P., Silva, V. B. S., Kousky, V. E., Wayne Higgins, R., and Janowiak, J. E.: Assessing objective techniques for gauge-based analyses of global daily precipitation, J Geophys Res, 113, D04110, doi:10.1029/2007JD009132, URL http: //dx.doi.org/10.1029/2007JD009132, 2008.

Findell, K. L., Gentine, P., Lintner, B. R., and Kerr, C.: Probability of afternoon precipitation in eastern United States and Mexico enhanced by high evaporation, Nature Geosci, 4, 434-439, doi:10.1038/ngeo1174, URL http://www.nature.com/doifinder/ 10.1038/ngeo1174, 2011.

Holwerda, F., Bruijnzeel, L., Scatena, F., Vugts, H., and Meesters, A.: Wet canopy evaporation from a Puerto Rican lower montane rain forest: The importance of realistically estimated aerodynamic conductance, J Hydrol, 414-415, 1-15, URL http: //www.sciencedirect.com/science/article/pii/S0022169411004896, 2012.

Hsu, K.-l., Gao, X., Sorooshian, S., and Gupta, H. V.: Precipitation Estimation from Remotely Sensed Information Using Artificial Neural Networks, J Appl Meteorol, 36, 1176-1190, doi:10.1175/1520-0450(1997)036〈1176:PEFRSI $\rangle 2.0 . C O ; 2$, URL http: //dx . doi.org/10.1175/1520-0450(1997)036<1176: PEFRSI>2 . 0.CO;2, 1997.

Huffman, G. J., Adler, R. F., Morrissey, M. M., Bolvin, D. T., Curtis, S., Joyce, R., McGavock, B., and Susskind, J.: Global Precipitation at One-Degree Daily Resolution from Multisatellite Observations, J Hydrometeorol, 2, 36-50, doi:10.1175/1525-7541(2001) 002 $\langle 0036$ :GPAODD $\rangle$ 2.0.CO;2, URL http://dx.doi.org/10.1175/1525-7541(2001) $002<0036$ : GPAODD $>2.0 . \mathrm{CO} ; 2,2001$.

Pearce, A. J., Rowe, L. K., and Stewart, J. B.: Nighttime, wet canopy evaporation rates and the water balance of an evergreen mixed forest, Water Resour Res, 16, 955-959, doi:10.1029/WR016i005p00955, URL http://dx.doi.org/10.1029/ WR016i005p00955, 1980. 